\title{
Secondary Endoleak Management Following TEVAR and EVAR
}

\author{
Seyed Ameli-Renani ${ }^{1} \cdot$ Vyzantios Pavlidis $^{1} \cdot$ Robert A. Morgan $^{1,2}$ (])
}

Received: 27 December 2019/Accepted: 22 June 2020/Published online: 10 August 2020

(C) The Author(s) 2020

\begin{abstract}
Endovascular abdominal and thoracic aortic aneurysm repair and are widely used to treat increasingly complex aneurysms. Secondary endoleaks, defined as those detected more than 30 days after the procedure and after previous negative imaging, remain a challenge for aortic specialists, conferring a need for long-term surveillance and reintervention. Endoleaks are classified on the basis of their anatomic site and aetiology. Type 1 and type 2 endoleaks (EL1 and EL2) are the most common endoleaks necessitating intervention. The management of these requires an understanding of their mechanics, and the risk of sac enlargement and rupture due to increased sac pressure. Endovascular techniques are the main treatment approach to manage secondary endoleaks. However, surgery should be considered where endovascular treatments fail to arrest aneurysm growth. This chapter reviews the aetiology, significance, management strategy and techniques for different endoleak types.
\end{abstract}

Robert A. Morgan

rmorgan@sgul.ac.uk

1 Department of Radiology, St George's University Hospitals NHS Foundation Trust, London, UK

2 Vascular \& Cardiac Surgery Research Centre, St George's University of London, Cranmer Terrace, London SW17 ORE, UK

\section{Fact Sheet}

\section{A: Ten Most Important Points Regarding Secondary Endoleak Management Following TEVAR and EVAR}

1. CTA is the main imaging investigation for assessing and characterising secondary endoleaks.

2. EL1 endoleaks are high pressure and require prompt treatment.

3. The main endovascular therapeutic options for EL1 include EndoAnchors, aortic cuffs and embolisation.

4. EL2 are low pressure, often benign and only warrant treatment if associated with a sac size increase of at least $5 \mathrm{~mm}$.

5. An occult EL1 and EL3 should be considered and excluded when facing a suspected EL2 with increasing sac size.

6. Embolisation is the mainstay treatment for EL2 with increasing sac size

7. Techniques for catheterising the endoleak sac in EL2 include transarterial, transiliac paraendograft, direct sac puncture and transcaval embolisation.

8. Embolisation agents for both EL1 and EL2 embolisation include coils, and liquid embolics, including Onyx, glue and thrombin.

9. The outcomes of type 2 embolisation in experienced hands are very good if experts select the appropriate embolisation method for the specific patient anatomy and perform a technically complete embolisation.

10. Embolisation has a small but defined role in the management of endoleaks after TEVAR. 


\section{B: Five Most Important Numbers with Respect to Endoleak Management After EVAR and TEVAR}

11. The combined approach of DUS, CTA and MRI detects and characterises secondary endoleaks in $91 \%$ of cases.

12. Embolisation has a technical success above $95 \%$ and mid-term success of $80 \%$ for EVAR EL1a.

13. Embolisation of type 2 endoleaks is indicated for an increase in sac size of $5 \mathrm{~mm}$ on sequential imaging.

14. Regarding outcomes of embolisation for type 2 endoleaks, a recent review indicated that the technical success rate for direct sac puncture embolisation $(81 \%)$ is higher than transarterial embolisation (63) and a lower rate of recurrence (19\% vs $36 \%$ ).

15. Type 1 endoleaks occur in 3.3-16\% after TEVAR, and type 2 endoleaks occur in $3.3 \%$ of all TEVAR cases. Embolisation of left subclavian artery associated type 2 endoleaks has a technical and clinical success of $100 \%$.

\section{C: Key References}

1. Guo Q, Zhao J, Ma Y, Huang B, Yuan D, Yang Y, et al. A meta-analysis of translumbar embolization versus transarterial embolization for type II endoleak after endovascular repair of abdominal aortic aneurysm. J Vasc Surg [Internet]. 2019;1-7. Available from: https://doi.org/10.1016/j.jvs.2019.05.074

2. Ultee KHJ, Büttner S, Huurman R, Bastos Gonçalves F, Hoeks SE, Bramer WM, et al. Editor's Choice Systematic Review and Meta-Analysis of the Outcome of Treatment for Type II Endoleak Following Endovascular Aneurysm Repair. Eur J Vasc Endovasc Surg [Internet]. 2018 Dec [cited 2019 Dec 11];56(6):794-807. Available from: https://www.ncbi.nlm.nih.gov/pubmed/ 30104089

3. Ameli-Renani S, Pavlidis V, Morgan RA. Early and midterm outcomes after transcatheter embolization of type I endoleaks in 25 patients. J Vasc Surg. 2017;65(2).

\section{D: Two Messages About Endoleak Management Following TEVAR and EVAR}

1. The primary therapy for type 1,2 and 3 endoleaks after EVAR and TEVAR involves endovascular methods in the majority of cases. Many of the therapeutic options require the insertion of additional endografts in conjunction with additional endovascular methods, e.g. EndoAnchors, chimneys, etc.

2. Embolisation plays a key role in the treatment of type 2 endoleaks and EVAR and TEVAR. Embolisation plays a small, but significant role in the management of challenging type 1 endoleaks after EVAR and TEVAR if no other endovascular solution is feasible.

\section{E: Prediction for the Next Five Years}

The therapeutic algorithm for all endoleaks will continue as described in this manuscript. It would be surprising to see any significant therapeutic advances or change in the approach to the management of any of the endoleak types. However, with increasing recognition that treating patients with hostile proximal necks by standard EVAR, and with the potential ramifications of planned UK NICE EVAR guidelines, we may see a significant reduction in the frequency of type 1a endoleaks after EVAR.

\section{Introduction}

Endovascular abdominal and thoracic aortic aneurysm repair (EVAR) and (TEVAR) have become the mainstay of therapy of many pathologies of the abdominal and thoracic aorta. Moreover, the development of complex endograft technologies such as fenestrated EVAR (FEVAR), branched EVAR (BEVAR) and parallel grafts enables increasingly challenging anatomy to be treated. However, despite the increased number of procedures and diversity of techniques, the management of endoleaks remains a challenge for aortic specialists. Endoleaks (EL) may compromise long-term endograft viability and some are associated with an increased risk of rupture, thereby necessitating long-term surveillance and secondary interventions. Thus, early detection and classification of endoleaks is crucial for optimal management planning. Endoleaks may be classified as primary or secondary endoleaks. Primary endoleaks appear within 30 days post-procedure and secondary (or late) endoleaks are detected more than 30 days after the procedure and after previous negative imaging. Endoleaks are also classified on the basis of their anatomic site and aetiology and are subdivided into five types (Table 1) [1]. Type 1 endoleak (EL1) is caused by inadequate apposition of the endograft to the vessel wall (attachment site) and is subclassified as EL 1a for proximal endoleak, EL 1b for distal attachment site endoleak and EL Ic for lack of seal by an iliac occlude plug in aorto-uni-iliac repair with a crossover graft; type 2 endoleak (EL2) involves perfusion of the aneurysm sac from collateral vessels; type 3 endoleak (EL3) describes stent graft component separation or endoleak due to a fabric tear; type 4 endoleak (EL4) represents an endoleak due to porosity of the graft; and type 5 endoleak (EL5), also known as endotension, is present when there is expansion of the sac without an apparent 
Table 1 Summary of classification of endoleaks and their management

\begin{tabular}{|c|c|c|}
\hline Endoleak & Cause of sac perfusion & Management \\
\hline 1 & Flow from the proximal or distal graft attachment site & Prompt \\
\hline a & Proximal graft attachment site & $\begin{array}{l}\text { Angioplasty, Palmaz or cuff extension, chimney extension and } \\
\text { embolisation }\end{array}$ \\
\hline $\mathrm{b}$ & Distal graft attachment site & Angioplasty and extension of distal limb \\
\hline $\mathrm{c}$ & Endoleak at the site of an iliac occluder plug & Insertion of an additional iliac occluder plug or embolisation \\
\hline 2 & $\begin{array}{l}\text { Retrograde flow through patent aortic side branch } \\
\text { vessels }\end{array}$ & Conservative if sac size stable Embolisation if sac size increase \\
\hline 3 & Mechanical graft failure & Prompt \\
\hline a & $\begin{array}{l}\text { Modular disconnection } \\
\text { Leak at a fenestration, branch or visceral stent }\end{array}$ & Placement of additional endograft components \\
\hline $\mathrm{b}$ & Fabric tear & \\
\hline 4 & Graft porosity & Conservative. Transient phenomenon \\
\hline 5 & Sac size increase with no visible endoleak & May consider catheter angiography with cone beam CT \\
\hline
\end{tabular}

endoleak on imaging. With developments in endograft fabric technology, type 4 endoleaks are of historical value and will not be further described. A wide range of treatment options exist including transarterial embolisation, percutaneous direct sac puncture embolisation, transcaval embolisation, surgical and conservative management. The criteria for best management should be tailored to each individual patient after careful planning and multidisciplinary team discussion.

This article is focused on the diagnosis and management of secondary type 1, 2 and 3 endoleaks after EVAR and TEVAR.

\section{Diagnosis of Secondary Endoleaks}

Numerous imaging modalities are available to detect and characterise endoleaks. However, factors such as the patient's BMI, anatomy, endoleak type and size, local expertise and costs play a role in deciding optimal imaging follow-up protocols.

CT angiography (CTA) appears to be the gold standard for the diagnosis of both thoracic and abdominal endoleaks. The technique is probably optimal when a pre-contrast scan followed by an arterial and delayed phase study is performed, with endoleaks best appreciated on the delayed phase imaging [2, 3]. However, due to increase radiation exposure and cost considerations [4], usually an arterial phase or a dual bolus scan is sufficient to depict the endoleak. Our institution primarily employs a single arterial phase protocol for standard EVAR and TEVAR follow-up, with dual and triple phase imaging reserved for problem solving.

Doppler and contrast-enhanced ultrasound (CEUS) are commonly used in surveillance after EVAR, providing an accessible and affordable modality, with no radiation and high accuracy when performed by an experienced operator.

Similarly, contrast-enhanced MRI/MRA does not expose the patient to ionising radiation. In some patients, contrast-enhanced MRI appears to be superior to CTA to demonstrate occult endoleaks Nevertheless, MRI is not included in routine follow-up protocols due to the high costs, the prolonged examination time, the restricted availability and the common use of MR-incompatible endografts.

Conventional catheter angiography and/or C-Arm CTA (e.g. DynaCT-Siemens, Germany) is used as a problemsolving tool when an endoleak cannot be classified, or if there is a sac size increase without a visible endoleak on non-invasive imaging. In practice, catheter angiography is seldom positive in these latter cases.

The combined approach of DUS, CTA and MRI can raise the detection rate of endoleaks to $91 \%$ [5]. However, the necessary lifelong surveillance of this patient group increases the costs of aortic repair by $50 \%$ [4]. State-of-theart imaging is crucial to guide optimal management for EVAR and TEVAR complications, especially endoleaks.

\section{Management of Secondary Endoleaks-EVAR}

\section{Type 1 Endoleaks}

Type 1 endoleaks occur in up to $9 \%$ of cases [6] and is recognised as an indication for reintervention due to the high risk for rupture in up to $52 \%$ of cases $[7,8]$. The risk of rupture is even higher $(3.37 \%)$ when there is a combination of high-pressure endoleaks EL1 and EL3. Type 1a endoleaks are related to adverse proximal neck anatomy and there is an increased risk of these as more challenging 
aortic aneurysms are treated using endografts.. Secondary EL1 occur in 2.2 to $15 \%$ [9, 10]. Early EL1a is a common complication $(30 \%)$ after snorkel/chimney EVAR technique, with high spontaneous resolution in up to $71.8 \%$ at 12 months and a low reintervention rate at 3.3\% [11]. Late EL1a has been reported in up to $7 \%$ of patients after chimney EVAR [9].

Type $1 \mathrm{~b}$ endoleak is caused by an inadequate seal at the distal landing zone. Late type $1 \mathrm{~b}$ endoleaks are reported in $2.3 \%$ at a mean follow-up of 32.8 months [10]. Similar to EL1a, EL1b are associated with an increase in sac size and aneurysm rupture.

\section{Management of Type 1a Endoleak}

Endovascular management of EL1a is mandatory, because of the documented risk of rupture. Technical success rates are high when managing intra-procedural or early EL1a, in the order of $90-100 \%$ [12-14]. Multiple options for reintervention are available, depending on the primary aortic repair technique that was used and the appearance on imaging. Standard techniques for primary endoleaks may include balloon dilatation and the insertion of giant balloon expandable stents in the neck to promote a proximal seal. However, these are seldom useful in secondary EL1a. Proximal endograft extension, either alone or in combination with chimney grafts, may be useful in selected patients with appropriate anatomy. More complex management options include FEVAR or BEVAR techniques. In addition, EndoAnchors (Medtronic, Santa Rosa, CA) provide proximal fixation of the endograft to the aortic wall with promising outcomes with technical success in 95\%, residual EL1a in $9.1 \%$ and freedom from reintervention in $94.4 \%$ of patients treated [15].

If patients do not respond, are unsuitable, or are unfit for the above techniques, transcatheter embolisation is an alternative approach that can be used to manage the EL1a. Embolisation has an increased role for EL1a after ChEVAR because of the limited alternative options available.

Embolisation technique: The most common access for the embolisation is the common femoral artery, although alternative routes can be used such as the transradial [16] and transbrachial routes [17-19].

The author's preferred technique (Fig. 1) is through a retrograde femoral approach to advance a $45 \mathrm{~cm}$ long, $6 \mathrm{~F}$ sheath (e.g. Destination, Terumo, Tokyo, Japan) to just below the top end of the endograft. An angiogram is performed from a flush catheter to depict the endoleak and to exclude additional other endoleak types. A reverse curve catheter (e.g. 5F Simmons; Cook Inc, Bloomington, Ind) with a hydrophilic wire is used to access the perigraft endoleak space. A dimethyl sulphoxide (DMSO) compatible microcatheter (e.g. 2.7F Progreat [Terumo Corp], Marathon or Echelon [Medtronic, Santa Rosa, Calif], or 2.95F PX SLIM [Penumbra, Alameda, Calif]) is advanced coaxially into the endoleak cavity. An endoleakogram is performed to better assess the size, geometry and the neck size and location of the endoleak nidus. The endoleakogram also enables the interventionist to evaluate for the presence of exit vessels, to find the best projection for the $\mathrm{C}$-arm to visualise the endoleaks and to also create a road map for the embolisation procedure. Depending to the anatomy of the endoleak nidus, embolisation is performed using either ethylene vinyl alcohol copolymer (Onyx,

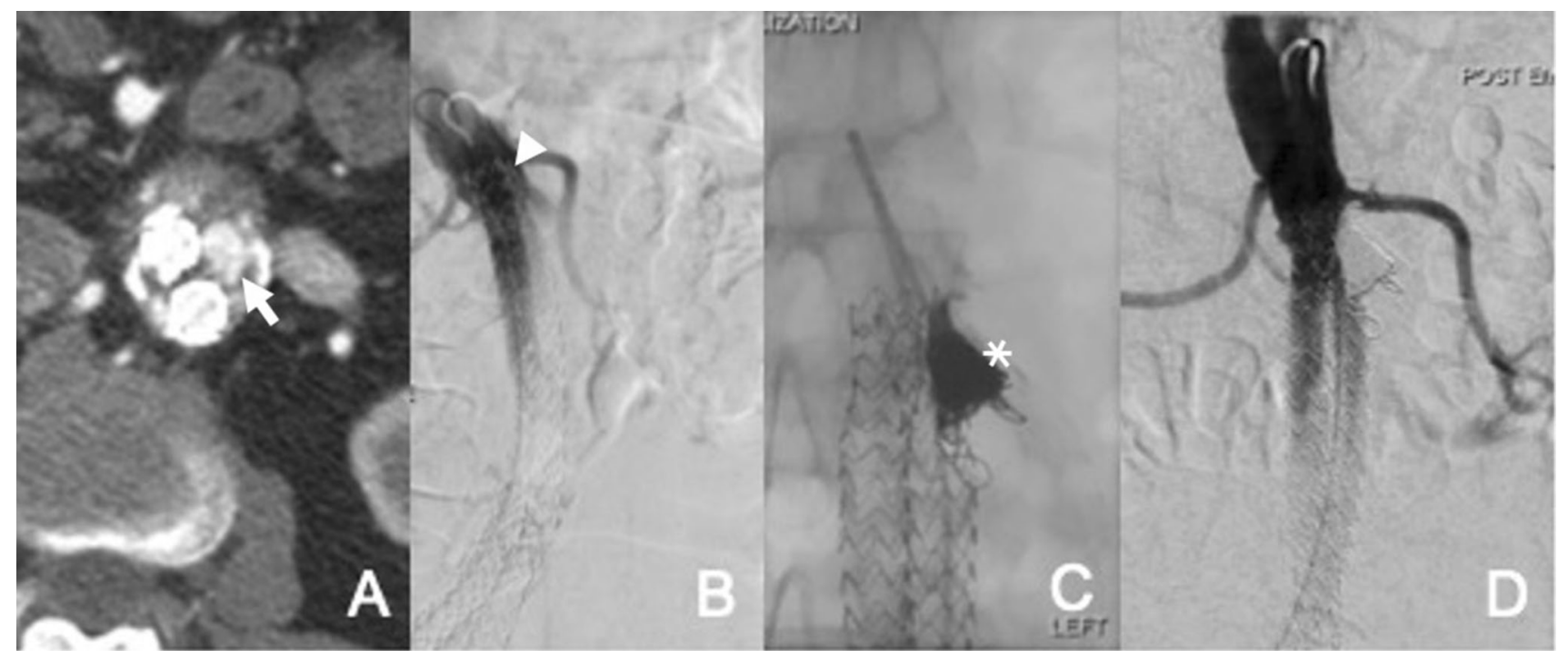

Fig. 1 EL1a embolisation. A Axial CT angiogram shows proximal EL1 in patient with a Nellix endograft (arrow). B Aortic angiograms confirm EL1a (arrow head). C Embolisation of the endoleak cavity with coils and Onyx via a microcatheter following catheterisation of the endoleak cavity with reverse shaped catheter (asterix). D Final angiogram shows successful endoleak embolisation 
Medtronic, Santa Rosa, Calif) alone or a combination of detachable coils (e.g. Ruby, Penumbra) and Onyx-34. Completion aortography is performed to assess for residual filling of the endoleak [20]. Complications are limited to puncture site access site hematomas and non-target embolisation with reflux of a small volume of the liquid embolic agent into the aorta, which is seldom clinically problematic.

Outcomes of embolisation: Embolisation is usually successful with immediate technical success (TS) approaching $100 \%$ in small series single-centre studies after EVAR (22 \& 25 patients), EVAS (7 patients) and chimney (9 patients) techniques [21-25]. Reports indicate successful embolisation can be achieved using coils, Onyx or glue ( $N$-butyl cyanoacrylate (NBCA)), or a combination [26-28] (Table 2).

\section{Management of Type 1b Endoleaks}

In general, these are easier to treat than EL1a endoleaks. Standard treatment consists of insertion of an additional endograft distally to achieve a distal seal. If there is insufficient space to extend to the origin of the internal iliac artery (IIA), then it is necessary to extend endograft coverage into the external iliac artery (EIA). The internal iliac artery can be overstented or embolised depending on whether there is a risk of a type 2 endoleak by covering the IIA (e.g. if the common iliac artery (CIA) is aneurysmal). Embolisation of the IIA can be performed with coils or plugs. In a two-centre study from 2018, 35 late $1 \mathrm{~b}$ endoleaks that were treated by endograft extension demonstrated a $100 \%$ TS rate, $100 \%$ freedom from re-intervention at a mean follow-up at 20 months and no requirement for open surgical treatment [29]. Additional novel technologies that allow the preservation of the IIA include iliac branched devices and parallel grafts. Embolisation has a role in a very small minority of patients if no other option is available or feasible. However, in reality this situation is very rare after EVAR as distal endograft extension, with or without preservation of the IIA is feasible.

\section{Summary of Secondary Type 1 Endoleaks After EVAR}

All current techniques available for managing EL1a, whether complex endovascular techniques such as FEVAR, BEVAR and ChEVAR, or simpler approaches such as EndoAnchors, embolisation techniques, cuff and/or Palmaz stent, demonstrate high technical and clinical success rates when used with the proper indication. Embolisation techniques, with success rates from 86 to $100 \%$, should be considered when there is insufficient neck length for stent graft extension, when the other techniques have failed, or when the patient is unfit for more complex therapies. When primary treatment involved chimney EVAR, embolisation techniques can be used as the first line treatment for a persistent secondary type 1a endoleak.

\section{Type 2 Endoleaks}

Secondary type 2 endoleaks (EL2) are the most common endoleaks following EVAR and remain the main cause of repeat intervention [30]. They occur despite complete exclusion of the aneurysm at the proximal and distal attachment sites. Type 2 endoleaks are caused by retrograde blood flow into the sac from branches of the endograft-covered native aorta or iliac vessels. There is usually one dominant inflow artery, most commonly the IMA or a lumbar artery, and often one or more outflow arteries. Patency of the IMA and one or more lumbar arteries preEVAR, as well as larger aneurysms and aneurysms with significant thrombus burden in the sac have found to increase the risk of developing type 2 endoleaks [31, 32]. Below, we will address the best approach to management of secondary type 2 endoleaks.

\section{Indications for intervention in Secondary Type 2 Endoleaks}

Whether to intervene or not and the exact point in time when to intervene for EL2 are a topic of ongoing debate [32-35]. EL2 are inherently low flow and are often transient, resolving following thrombosis of the aneurysm sac and reversal of anticoagulation. A recent meta-analysis of four major EVAR trials including 2783 patients showed an EL2 incidence of $11.7 \%$, a reintervention rate of $22 \%$ for these EL2 (99 of 435 detected EL2); and no evidence that EL2, whether treated or not treated were associated with worse survival [36]. In fact the risk of aneurysm rupture in the presence of an isolated type 2 endoleak is exceptionally low [33]. The current consensus is that one should treat a persistent EL2 when they are associated with a significant sac size increase, commonly considered as at least $5 \mathrm{~mm}$ over 6 months [37]. In the absence of an enlarging sac size, patients with type 2 endoleak should be kept under followup imaging by CTA or US based on standard local protocols.

Embolisation is the main treatment for EL2. The aim of intervention is to obliterate the endoleak cavity, which is analogous to the central nidus in a vascular malformation. This is best achieved by occlusion of the supplying arteries (e.g. IMA) as well as the endoleak cavity. There are a variety of embolisation techniques depending on the anatomy of the artery supplying the endoleak and the available route to access the endoleaks.

\section{Transarterial Embolisation}


Table 2 Main publications on outcomes of EL1 embolisation

\begin{tabular}{|c|c|c|c|c|c|c|c|}
\hline Years & Authors & $\mathrm{Pt}$ & Treatment & Embolic Material & $\begin{array}{l}\text { Technical } \\
\text { success }(\%)\end{array}$ & $\begin{array}{l}\text { Mean } \\
\text { follow-up } \\
\text { (months) }\end{array}$ & $\begin{array}{l}\text { Clinical } \\
\text { success } \\
(\%)\end{array}$ \\
\hline 2018 & $\begin{array}{l}\text { Ierardi et al. } \\
\text { [43] }\end{array}$ & 8 & Embolisation & $\begin{array}{l}\text { Onyx and coils in } 3 \text {, NBCA and Onyx in } 1 \text {, Onyx } \\
\text { and coils in } 1\end{array}$ & $100(8 / 8)$ & 16.8 & $\begin{array}{c}100(8 / \\
8)\end{array}$ \\
\hline 2018 & $\begin{array}{l}\text { Stenson et al. } \\
\text { [44] }\end{array}$ & 15 & $\begin{array}{l}9 \text { Embolisations } 6 \\
\text { proximal } \\
\text { extensions }\end{array}$ & Onyx + coils & $1009 / 9$ & 36 & - \\
\hline 2017 & $\begin{array}{l}\text { van de Ham } \\
\text { et al. [45] }\end{array}$ & 40 & $\begin{array}{l}17 \text { Embolisations } \\
13 \text { OC } 10 \mathrm{Ch}- \\
\text { EVAS }\end{array}$ & Onyx \pm coils & $\begin{array}{l}96.5 \\
\text { (overall } \\
\text { EL1 } \\
\text { treatment) }\end{array}$ & $1-6$ & - \\
\hline 2017 & $\begin{array}{l}\text { Marcelin } \\
\text { et al. [23] }\end{array}$ & 9 & Embolisation & Onyx \pm coils & $1009 / 9$ & $15.9 \pm 11.36$ & $898 / 9$ \\
\hline 2017 & $\begin{array}{l}\text { Ameli- } \\
\text { Renani } \\
\text { et al. [21] }\end{array}$ & 25 & Embolisation & Onyx \pm coils & $100(25 / 25)$ & 10 & $80-85$ \\
\hline 2017 & $\begin{array}{l}\text { Graif et al. } \\
\text { [46] }\end{array}$ & 8 & $\begin{array}{l}\text { Embolisation } 6 \\
\text { ELIa, } 2 \text { ELIb }\end{array}$ & Onyx \pm coils & $88(7 / 8)$ & 6.9 & $71(5 / 7)$ \\
\hline 2015 & $\begin{array}{l}\text { Gandini et al. } \\
\text { [17] }\end{array}$ & 1 & $\begin{array}{l}\text { Transcaval } \\
\text { Embolisation }\end{array}$ & $\begin{array}{l}\text { Cuff Zenith (Cook Medical, Bloomington, Ind) and } \\
\text { thrombin and coils }\end{array}$ & $100(1 / 1)$ & 12 & $\begin{array}{c}100(1 / \\
1)\end{array}$ \\
\hline 2014 & $\begin{array}{l}\text { Eberhardt } \\
\text { et al. [47] }\end{array}$ & 8 & $\begin{array}{l}\text { Embolisation } 6 \\
\text { ELIa, } 1 \text { ELIb, } 1 \\
\text { ELIa \& ELIb }\end{array}$ & Onyx \pm coils & $100(8 / 8)$ & $13.2(8-24)$ & $88(7 / 8)$ \\
\hline 2013 & $\begin{array}{l}\text { Katada et al. } \\
\text { [48] }\end{array}$ & 1 & $\begin{array}{l}\text { Embolisation and } \\
\text { cuff }\end{array}$ & $\begin{array}{l}\text { Coils NBCA-lipiodol embolisation was performed } \\
\text { (B), then the Zenith TX2 extension cuff (Cook } \\
\text { Medical, Bloomington, Ind) }\end{array}$ & $100(1 / 1)$ & 6 & $\begin{array}{c}100(1 / \\
1)\end{array}$ \\
\hline 2011 & $\begin{array}{l}\text { Henrikson } \\
\text { et al. [27] }\end{array}$ & 6 & $\begin{array}{l}\text { Embolisation } 5 \\
\text { ELIa, } 1 \text { ELIb }\end{array}$ & Onyx & $100 \%(6 / 6)$ & $3-18$ & $\begin{array}{r}100 \% \\
(6 / 6)\end{array}$ \\
\hline 2011 & $\begin{array}{l}\text { Choi et al. } \\
\text { [49] }\end{array}$ & 7 & $\begin{array}{l}\text { Embolisation and } \\
\text { cuff }\end{array}$ & $\mathrm{N}-\mathrm{BCA} \pm$ coils & $86 \%(6 / 7)$ & $18(0-53$ & $\begin{array}{c}86 \%(6 / \\
7)\end{array}$ \\
\hline 2010 & Lu et al. [50] & 42 & $\begin{array}{l}\text { Embolisation } 5 \\
\text { ELIa, } 1 \text { ELIb, } 1 \\
\text { EL1a \& ELIb }\end{array}$ & N-BCA or Onyx \pm coils, fibrin glue injection & $98 \%(41 / 42)$ & 40 & $\begin{array}{l}83 \% \\
(35 / \\
42)\end{array}$ \\
\hline 2010 & $\begin{array}{l}\text { Grisafi et al. } \\
\text { [51] }\end{array}$ & 1 & Onyx & $\begin{array}{l}\text { Embolisation device, Onyx (Micro Therapeutics } \\
\text { Inc, Irvine, Calif) }\end{array}$ & $100 \%(1 / 1)$ & 12 & $\begin{array}{r}100 \% \\
(1 / 1)\end{array}$ \\
\hline 2010 & $\begin{array}{l}\text { Loffroy et al. } \\
\text { [52] }\end{array}$ & 1 & $\begin{array}{l}\text { Transarterial } \\
\text { microcoil } \\
\text { Embolisation }\end{array}$ & $\begin{array}{l}\text { Detachable microcoils into the nidus while an intra- } \\
\text { aortic balloon catheter was inflated at the same } \\
\text { time }\end{array}$ & $100 \%(1 / 1)$ & 6 & $\begin{array}{l}100 \% \\
(1 / 1)\end{array}$ \\
\hline 2005 & $\begin{array}{l}\text { Golzarian } \\
\text { et al. [53] }\end{array}$ & 32 & $\begin{array}{l}\text { Embolisation } 32 \\
\text { ELIa }\end{array}$ & Coils with or without gelatin sponge or thrombin & $91 \%(29 / 32)$ & 38.6 & $\begin{array}{l}91 \% \\
(20 / \\
22)\end{array}$ \\
\hline 2003 & $\begin{array}{l}\text { Maldonando } \\
\text { et al. [54] }\end{array}$ & 17 & $\begin{array}{l}\text { Embolisation } 13 \\
\text { ELIa, 4ELIb }\end{array}$ & 10 n-BCA, 3 coils, 4 cuff & $94 \%(16 / 17)$ & $6.9(0-19)$ & $\begin{array}{c}88 \% \\
(15 / \\
17)\end{array}$ \\
\hline 1999 & $\begin{array}{l}\text { Amesur et al. } \\
\text { [55] }\end{array}$ & 5 & $\begin{array}{l}\text { Embolisation } 1 \\
\text { ELIa, } 4 \text { ELIb }\end{array}$ & Coils & $100 \%(5 / 5)$ & $8(3-17)$ & $\begin{array}{r}100 \% \\
(5 / 5)\end{array}$ \\
\hline
\end{tabular}

The most common technique is transarterial catheterisation of the dominant feeding vessel via communicating arteries supplying the vessel. This approach is performed under conscious sedation and requires an accessible route from an aortoiliac vessel, via collaterals to the vessel feeding the endoleak and ideally the endoleak cavity itself.
The technical success of this approach is limited if the responsible feeding vessel cannot be cannulated or if a viable path to the endoleak cavity cannot be found. Transarterial embolisation is most successful for endoleaks originating from the IMA (Fig. 2). For embolisation of IMA endoleaks, a long 6-F sheath is inserted via a common 
femoral artery access and the tip placed at the SMA origin. A reverse-curve catheter (e.g. Simmons) is used to catheterise the SMA and an angiogram is performed: a. to confirm filling of the endoleak cavity via retrograde filling of the IMA and b. to depict the route to the IMA via the middle colic branch of the SMA and the left colic branch of the IMA. The sheath is advanced into the SMA to provide additional support. A hydrophilic 0.035 inch guidewire is advanced into the middle colic artery, followed by the selective catheter. A microcatheter is advanced coaxially through the middle colic branches of the SMA, into the left colic artery and subsequently into the IMA and the endoleak cavity. Embolisation is commonly performed using liquid embolics including glue and Onyx, although use of other agents such as gelfoam and thrombin have also been reported. The authors prefer using either a liquid embolic agent alone (Onyx or Glubran), or a combination of pushable coils and a liquid embolic.

Type 2 endoleaks arising from iliolumbar arteries can be treated in a similar manner (Fig. 3). The main difference to the above is the use of a short 6-F sheath placed in the ipsilateral femoral artery, using an appropriate catheter to catheterise the internal iliac artery (e.g. Sos Omni) and advancing a microcatheter coaxially via the ascending iliolumbar artery into the feeding lumbar artery or ideally the endoleak cavity. A steerable sheath may be helpful in some
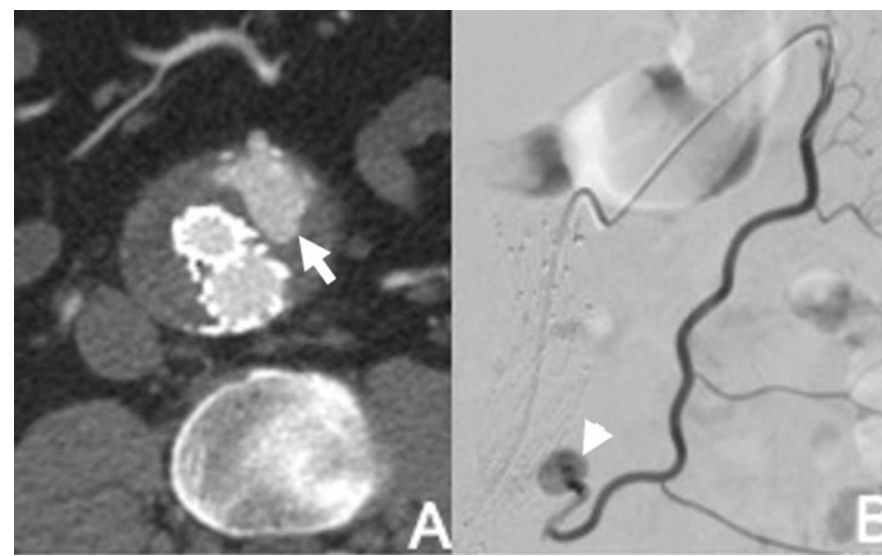

Fig. 2 Transarterial embolisation of type 2 endoleak. A Axial CT image shows endoleak arising close to origin of IMA (arrow). B Angiogram via microcatheter placed into middle colic branch of SMA confirms endoleak (arrow head). C Microcatheter passed into

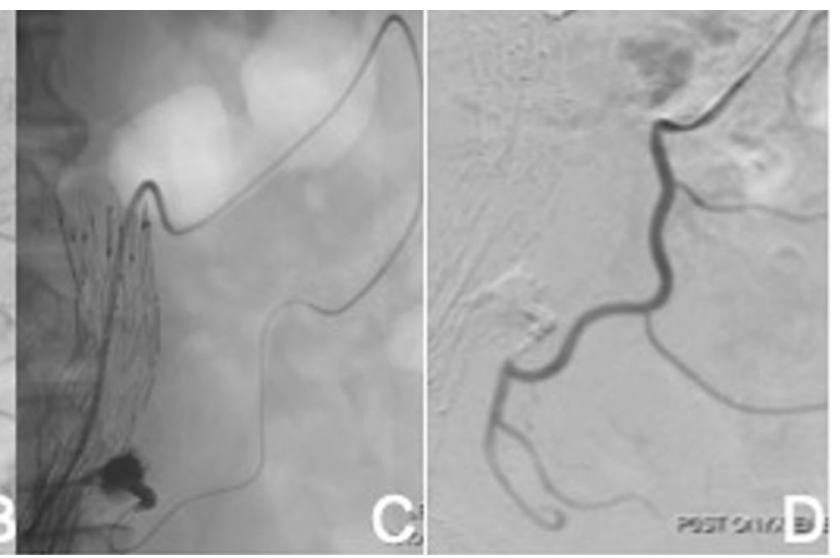

endoleak cavity via the left colic branch of the IMA, and embolisation performed with Onyx. D Completion angiogram shows no further filling of endoleak
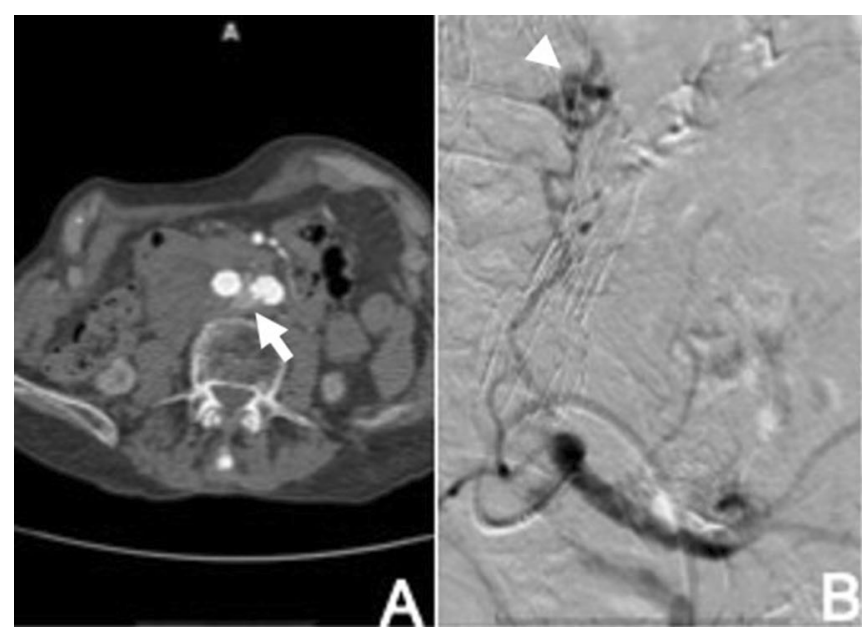

Fig. 3 Transarterial embolisation of type 2 endoleak arising from iliolumbar artery. A Axial CT image shows endoleak arising from a left lumbar artery (arrow). B Angiogram following catheterisation of the left internal iliac artery shows filling of the endoleak cavity (nidus) by the left lumbar artery (arrowhead). C Angiogram following
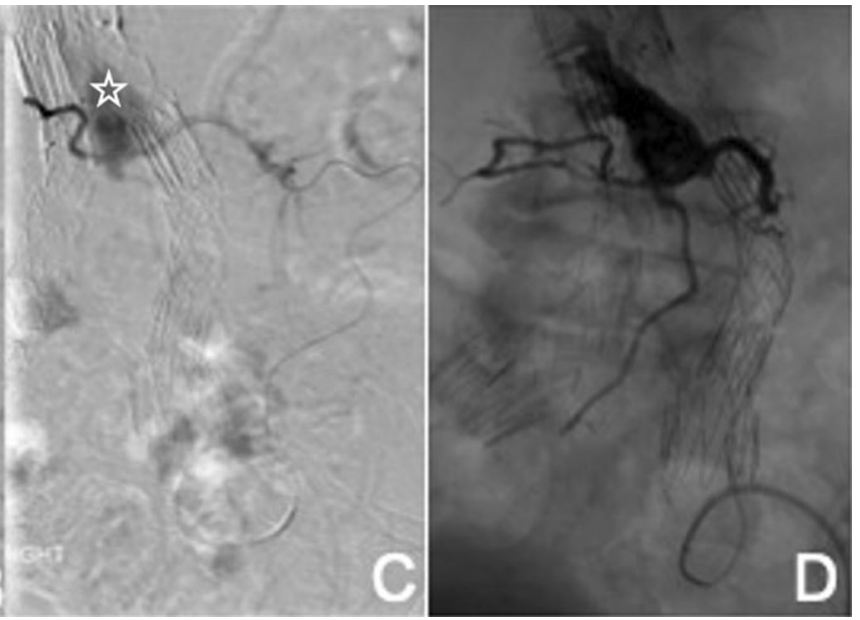

selective microcatheter catheterisation of the endoleak cavity through the tortuous iliolumbar artery shows endoleak cavity (asterix) and several exit vessels. D Complete embolisation of endoleak cavity and exiting branches using Onyx 
cases. This approach is more challenging with a lower success rate compared to IMA endoleak embolisation, because of the difficulty cannulating the responsible lumbar feeding vessel through the frequently tortuous and small caliber arterio-arterial communications.

In these cases, if the endoleak cavity cannot be accessed, it may be possible to successfully embolise the endoleak by injecting a low viscosity Onyx preparation (Onyx 18) from a more proximal location, which may flow gradually into the endoleak cavity [38]. However, proximal embolisation of the iliolumbar artery itself without occlusion of the endoleak cavity may result in recurrence from other collateral vessels that may supply the endoleak cavity.

Outcomes of transarterial embolisation: There is a relatively wide spread of reported technical and clinical success rates for this technique (Table 3), which is reflected in several meta-analysis and systemic reviews published recently [36, 37, 39]. One of the largest single cohorts published in 2012 of 95 patients undergoing 140 embolisation procedures (predominantly transarterial but a few other techniques too), using a range of embolics (glue $61 \%$, coils 29\%, glue and coils $7 \%$ and Gelfoam 3\%) showed $81.5 \%$ freedom from aneurysm sac expansion at one year but a significant decrease to $43.7 \%$ at five years, with an associated increase in the number of repeat embolisation procedures required [40]. The high long-term failure rate may in part reflect failure to completely occlude the endoleak cavity due to shortcomings of earlier techniques such as embolising the feeding vessel but not the endoleak cavity and performing embolisation using coils alone without liquid embolic.
There is no consensus on the optimal embolic agent or combination of embolic agents for transarterial embolisation.

Where conventional transarterial embolisation is not possible or fails, other techniques may achieve access to the endoleak cavity for embolisation. These include transiliac paraendograft embolisation (TIPE), direct sac puncture and transcaval embolisation.

\section{Transiliac Paraendograft Embolisation (TIPE)}

TIPE is a novel technique for treating type 2 endoleaks that cannot be accessed by the standard transarterial route and involves passing a catheter and hydrophilic wire into the potential space between the iliac limb endograft and the vessel wall. Once access into the paraendograft space is obtained, the catheter and wire are advanced superiorly using standard catheter-guidewire manipulation techniques between the graft and the artery wall until access to the sac thrombus is achieved. Further catheter-guidewire manipulation within the sac thrombus may enable the interventionist to access the endoleak nidus itself, which is heralded by blood flow from the catheter. After performing an endoleakogram to define the anatomy of the endoleak, the nidus and any visible and accessible feeding vessels are embolised with a liquid embolic and coils or a combination of these agents. This technique can be performed during the same procedure as a failed attempt at conventional transarterial embolisation.

Using this technique, Coppi and colleagues reported successful embolisation of the sac in 16 of 17 patients [41] using a 9F sheath, with one adverse event of a procedural

Table 3 Main publications on outcomes of EL2 transarterial embolisation, published since 2009

\begin{tabular}{|c|c|c|c|c|c|c|c|}
\hline Authors & $\begin{array}{l}\text { No. of } \\
\text { endoleak } \\
\text { cases }\end{array}$ & $\begin{array}{l}\text { Patient } \\
\text { population }\end{array}$ & Embolic material & $\begin{array}{l}\text { Technical } \\
\text { success } \\
(\%)\end{array}$ & $\begin{array}{l}\text { Follow-up } \\
\text { length mean- } \\
\text { months (range) }\end{array}$ & $\begin{array}{l}\text { Clinical } \\
\text { success } \\
(\%)\end{array}$ & Additional comments \\
\hline $\begin{array}{l}\text { Ribe et al. } \\
\text { [79] }\end{array}$ & 18 & 600 & Onyx & $18(100)$ & $19(3-60)$ & $16(89)$ & $\begin{array}{l}\text { EL2 source: IIA in } 7, \text { IMA in } 7 \\
\text { and lumbar artery in } 4 \text { cases }\end{array}$ \\
\hline $\begin{array}{l}\text { Wojtaszek } \\
\text { et al. } \\
\text { [80] }\end{array}$ & 22 & 22 & Onyx & $17(77)$ & $17(3-38)$ & $17 / 21(81)$ & \\
\hline $\begin{array}{l}\text { Hongo } \\
\text { et al. } \\
\text { [81] }\end{array}$ & 20 & 20 & NBCA and coils & $18(90)$ & $18.5(6-36)$ & $13(65)$ & \\
\hline $\begin{array}{c}\text { Müller- } \\
\text { Wille } \\
\text { et al. } \\
{[82]}\end{array}$ & 11 & 11 & Onyx & $6(55)$ & $26(6-50)$ & $8(73)$ & $\begin{array}{l}\text { Clinical success defined as no } \\
\text { increase in sac size on } \\
\text { follow-up imaging }\end{array}$ \\
\hline $\begin{array}{l}\text { Funaki } \\
\text { et al. } \\
\text { [83] }\end{array}$ & 16 & 25 & $\begin{array}{l}\text { Cyanoacrylate, coils and } \\
\text { ethylene vinyl alcohol } \\
\text { copolymer }\end{array}$ & $14(88)$ & $27.5(6-88)$ & $16(100)$ & $\begin{array}{l}\text { Clinical success defined as no } \\
\text { increase in sac size on } \\
\text { follow-up imaging }\end{array}$ \\
\hline
\end{tabular}

Internal iliac artery (IIA), Inferior mesenteric artery (IMA) 
type Ib endoleak. In the authors experience, paraendograft access with a $4 / 5 \mathrm{Fr}$ catheter alone or a $6 \mathrm{Fr}$ sheath is technically adequate and minimises the risk of a procedural type $\mathrm{Ib}$ endoleak [42]. In practice, procedural success is limited by difficulty in accessing the paraendograft space and accessing the endoleak nidus even when the sac thrombus has been accessed. Embolisation of the sac thrombus if the nidus cannot be accessed is of no benefit.

\section{Direct Sac Puncture}

This involves the direct percutaneous puncture of the aneurysm sac. It is most commonly performed via a translumbar approach with the patient positioned prone on the operating table but may also be performed transabdominally [56] when there is an anterior endoleak. It can be performed under general anaesthesia, or under sedation and local anaesthesia, depending on the patient and the potential difficulty of the procedure. Prior CT imaging is initially reviewed to assess the approach to the endoleak cavity. Access is obtained using fluoroscopic guidance or targeted $\mathrm{C}$-arm CT software available on most modern angiographic equipment. An 18 or $20 \mathrm{G}$ coaxial needle is advanced until there is brisk, pulsatile blood flow through the needle, indicating a satisfactory position within the endoleak cavity. An angiogram is performed to depict the anatomy of the endoleak and to plan the subsequent embolisation. At this point, the needle is exchanged for a 4,5 or 6 Fr sheath over a stiff guidewire wire and a short selective catheter (e.g. KMP, Bolia, Cobra) is advanced into the endoleak cavity. With the catheter tip located in a stable position in the endoleak nidus, a microcatheter is advanced into the endoleak. If feeding vessels are visualised and can be catheterised, these should be embolised first with coils, a liquid embolic or small plugs. It may not be possible to access any feeding arteries, and strenuous and lengthy efforts should not be made to do this as embolisation of the nidus is the main aim of this procedure. After embolisation of any feeding arteries, the nidus is embolised with a liquid embolic, coils or a combination (Fig. 4).
Outcomes of Direct Sac Puncture Embolisation: There are only two papers that have specifically reported the outcomes of direct sac puncture embolisation $[56,57]$. In the larger of these studies, Zener et al. (2018) reported on 33 transabdominal embolisations in 30 patients using a range of embolic agents with a technical success rate of $97 \%$ and clinical success of $85 \%$, defined as freedom from sac growth (Table 4).

There are several papers that report outcomes comparing direct sac puncture and transarterial embolisation [58-62]. Recently a systematic review of 32 studies comprising 393 interventions for type II endoleak, compared outcomes for translumbar embolisation and transarterial embolisation. The review reported that translumbar embolisation had a higher technical success rate ( $81 \%$ vs. $63 \%$ ), fewer cases of endoleak recurrence (19\% vs 36\%) and a lower complication rate ( $0 \%$ vs $9 \%$ ) when compared with transarterial embolisation [63]. However, this review includes data from a heterogenous cohort of studies using a variety of techniques and embolic agents conducted retrospectively, and its overall conclusion that direct sac puncture is more effective than transarterial embolisation remains open to question. Clearly, one must remember that many interventionists select the embolisation method on a case-bycase basis dependent on the anatomy of the endoleak and their perception regarding which technique is likely to be more likely to be successful. Therefore, in the absence of evidence from randomised studies comparing techniques, the reviewer must bear this in mind. It is the author's opinion, that if an expert interventionist in all methods selects the specific technique based on the vascular anatomy, then the outcomes of a technically complete embolisation should be comparable, whichever technique is used.

\section{Transcaval Embolisation}

In this technique, transcaval access into the endoleak cavity is achieved by using an angled-tip catheter and an angled sheathed needle (e.g. TIPSS set) to penetrate the IVC wall and enter the endoleak cavity. There is limited

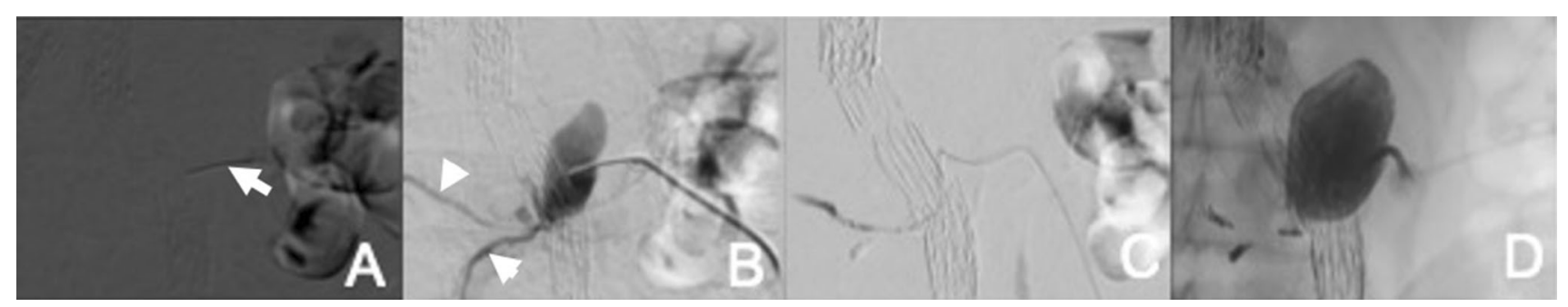

Fig. 4 Direct sac puncture and embolisation of type 2 endoleak. A Fluoroscopic guided access into the endoleak cavity via $18 \mathrm{G}$ Chiba needle (arrow), using bony landmarks and aortic endograft markers. B Angiogram via $18 \mathrm{G}$ needle confirms endoleak cavity (nidus) and several exit vessels (arrow heads). C Embolisation of exit vessels with micro-coils via microcatheter. D Subsequent embolisation of the endoleak cavity with Onyx 
Table 4 Main publications directly assessing outcomes of direct sac puncture and embolisation for EL2

\begin{tabular}{|c|c|c|c|c|c|c|c|}
\hline Authors & $\begin{array}{l}\text { No. of } \\
\text { endoleak } \\
\text { cases }\end{array}$ & $\begin{array}{l}\text { Patient } \\
\text { population }\end{array}$ & Embolic material & $\begin{array}{l}\text { Technical } \\
\text { success } \\
(\%)\end{array}$ & $\begin{array}{l}\text { Follow-up } \\
\text { length mean- } \\
\text { months (range) }\end{array}$ & $\begin{array}{l}\text { Clinical } \\
\text { success } \\
(\%)\end{array}$ & $\begin{array}{l}\text { Transabdominal } \\
\text { or Translumbar }\end{array}$ \\
\hline $\begin{array}{l}\text { Zener et al. } \\
\text { [56] }\end{array}$ & 33 & 30 & $\begin{array}{l}\text { Glue only }(45.5 \%) \text {, glue/coils }(36.4 \%) \\
\text { and Onyx with or without glue/coils } \\
(18.1 \%)\end{array}$ & $29(97)$ & 15 & $23 / 27(85)$ & $\begin{array}{l}\text { All } \\
\text { transabdominal }\end{array}$ \\
\hline $\begin{array}{l}\text { Carrafiello } \\
\text { et al. } \\
\text { [57] }\end{array}$ & 8 & 8 & $\begin{array}{l}\text { Thrombin only in } 5 \text { cases, thrombin } \\
\text { and glue in } 2 \text { cases and Onyx in } 1 \\
\text { case }\end{array}$ & $8(100)$ & $36(24-46)$ & $8(100)$ & All translumbar \\
\hline
\end{tabular}

data on this technique, which is summarised in Table 5. The largest cohort included 29 patients, reported by Giles et al. [86], with technical success achieved in $90 \%$ and no significant adverse events, although 5 patients required reintervention.

\section{Surgery}

Surgical options include laparoscopic clipping of the lumbar or inferior mesenteric arteries, surgical fixation of the endograft to the aortic wall or open aneurysmectomy. These are treatments of last resort for cases where the above techniques have been unsuccessful or not feasible. In view of the increasing variety of embolisation techniques available, surgical intervention is seldom required.

\section{Selecting the Best Approach to Manage Type 2 Endoleaks}

As described, there is a range of embolisation techniques that may be utilised for EL2. In some cases, more than one technique may be undertaken to achieve embolisation. Figure 5 illustrates a summary of the author's practice in managing EL2.

In principle, when faced with a suspected EL2 and increasing sac size, it is imperative to consider the possibility of an occult type 1 or type 3 endoleak disguised as a type 2 endoleak, where opacified aortic side branches are acting as exit vessels rather entrance vessels. CT imaging is usually sufficient for this, but if CTA is inconclusive, catheter aortography (sometimes combined with conebeam CT) can be used to help confirm the source of the endoleak and to plan treatment. Contrast-enhanced ultrasound enables real-time imaging of arterial flow into the endoleak and can be useful as a problem solving tool, particularly for assessment of the type and anatomy of endoleaks.

A catheter angiogram with a view to direct transarterial embolisation is usually the first intervention. If the endoleak is arising from retrograde flow in the IMA, a direct coaxial microcatheter catheterisation via the SMA is usually feasible. Endoleaks arising from a lumbar or iliolumbar branch are often less amenable to transarterial embolisation than IMA embolisation. Nevertheless, transarterial embolisation of a lumbar EL2 should be still attempted at the time of the diagnostic catheter angiogram. If transarterial embolisation is unsuccessful, a transiliac paraendograft catheterisation of the endoleak sac can be attempted during the same sitting. If these are unsuccessful, consideration should be given to utilising the alternative access routes of percutaneous direct sac puncture or the transcaval route. It is the author's preference to schedule these at a later date as a separate procedure.

\section{Type 3 Endoleaks}

Type 3 endoleaks result from a structural defect of the endograft, and can be subdivided into EL 3a, caused by component modular disconnection and EL 3b, secondary to a fabric tear. They are relatively uncommon, and increasingly so with modern stent graft designs. A recent retrospective study of 967 EVAR cases reported type 3 endoleaks in $12.7 \%$ for first and second generation endografts and $1.3 \%$ in third generation endografts [64]. These are high flow endoleaks similar to type 1 endoleaks, resulting in sac pressurisation and therefore EL3 mandate immediate treatment. The standard treatment is relining the endograft by deploying a new endograft within the preexisting graft. There are a few isolated case reports of embolisation of EL3 where relining is not possible or fails.

\section{Type 5 Endoleaks}

These are also termed 'endotension' and are defined as an increase in sac size in the absence of an identifiable endoleak. When assessing potential cases, catheter angiography together with cone beam CT may be useful in excluding the presence of an endoleak or another cause for sac expansion. If no cause is found, observation may be a valid option for some of these cases, as these endoleaks are not directly associated with high pressure, but the criteria for conservative management are unclear [36]. Options for intervention in cases of increasing aneurysm sac size include the use of extension cuffs, relining the endograft and conversion to open repair [65]. 
Table 5 Main publications directly assessing outcomes of transcaval embolisation for EL2

\begin{tabular}{|c|c|c|c|c|c|c|c|}
\hline Authors & $\begin{array}{l}\text { No. of } \\
\text { endoleak } \\
\text { cases }\end{array}$ & $\begin{array}{l}\text { Patient } \\
\text { population }\end{array}$ & Embolic material & $\begin{array}{l}\text { Technical } \\
\text { success } \\
(\%)\end{array}$ & $\begin{array}{l}\text { Follow-up length } \\
\text { mean-months } \\
\text { (range) }\end{array}$ & $\begin{array}{l}\text { Clinical } \\
\text { success } \\
(\%)\end{array}$ & Additional comments \\
\hline $\begin{array}{l}\text { Scali et al. } \\
\text { [84] }\end{array}$ & 6 & 6 & Coils + thrombin & $6(100)$ & $8.1(2-22)$ & $4(66)$ & $\begin{array}{l}\text { Thrombin used in } 2 \text { IV ultrasound in } 4 \\
\text { and intraoperative CT in } 2 \text { cases }\end{array}$ \\
\hline $\begin{array}{l}\text { Gandini } \\
\text { et al. } \\
\text { [85] }\end{array}$ & 29 & 26 & $\begin{array}{l}\text { Coils }+ \text { glue/ } \\
\text { thrombin }\end{array}$ & $9(100)$ & $25(14-31)$ & $25(86)$ & $\begin{array}{l}\text { Feeding artery also embolised in } 20 \\
\text { cases, all with no recurrence }\end{array}$ \\
\hline $\begin{array}{l}\text { Giles } \\
\text { et al. } \\
\text { [86] }\end{array}$ & 29 & 29 & Coils + thrombin & $24(83)$ & $16.5( \pm 10.4)$ & $20(70)$ & $\begin{array}{l}\text { Thrombin injection used in } 5 \text {, IV } \\
\text { ultrasound in } 4 \text { and intra operative } \\
\text { CT in } 5 \text { cases }\end{array}$ \\
\hline $\begin{array}{l}\text { Mansueto } \\
\text { [87] }\end{array}$ & 12 & 12 & Coils + thrombin & $11(92)$ & 12 & $10(83)$ & $\begin{array}{l}\text { Thrombin injection used in } 5 \text {, IV } \\
\text { ultrasound in } 4 \text { and intra operative } \\
\text { CT in } 5 \text { cases }\end{array}$ \\
\hline
\end{tabular}

Fig. 5 Summary of author's approach to management of type 2 endoleaks

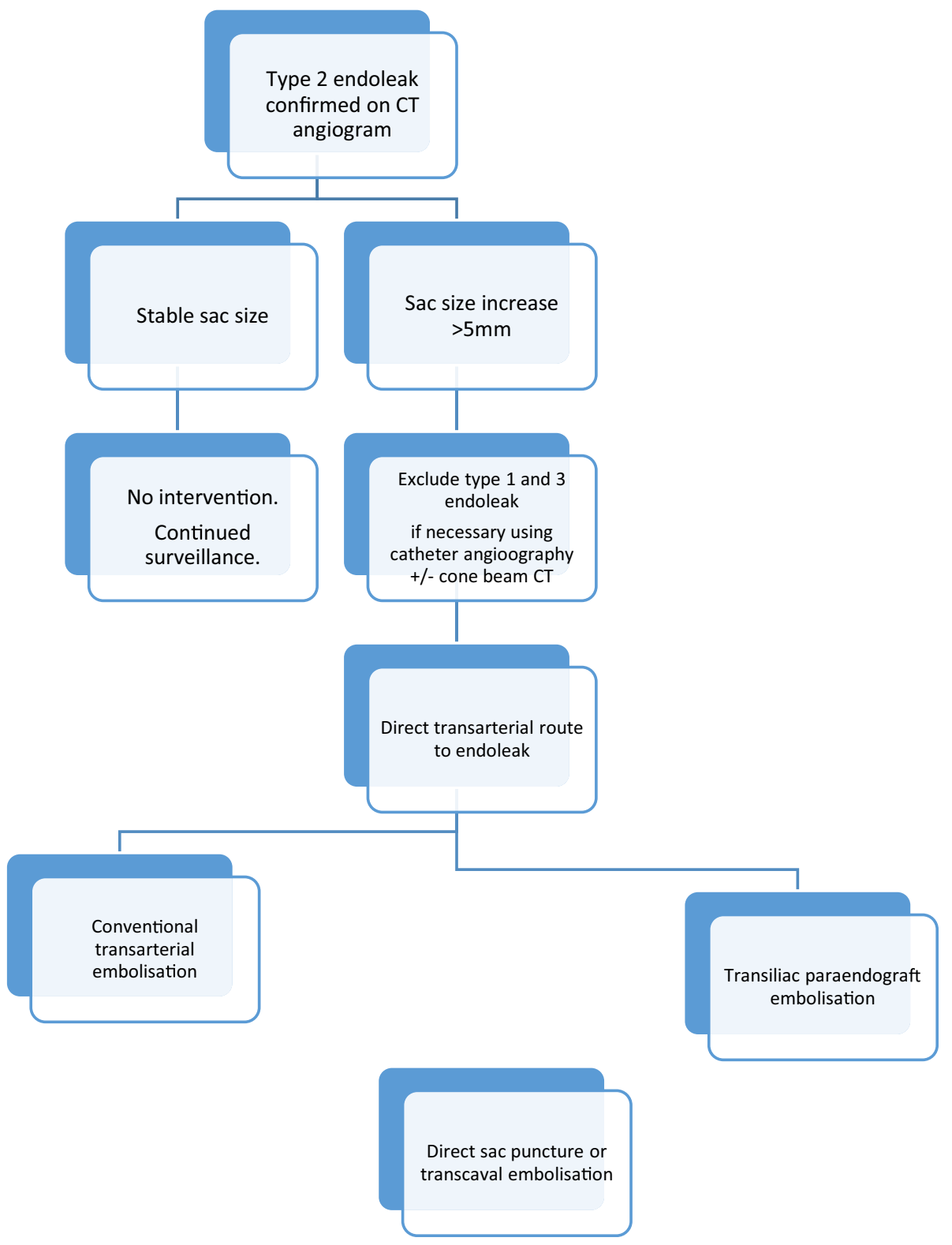




\section{Management of Secondary Endoleaks-TEVAR}

Thoracic aortic aneurysms (TAAs) affect 10.4 in 100,000 people per year, with an estimated incidence of rupture and dissection at 3.5 per 100,000 per year, with a high $(90 \%)$ mortality rate in cases of acute rupture $[66,67]$ The aim of TEVAR is to reduce these risks and many studies have confirmed favourable long-term outcomes after endovascular repair. Overall, all types of endoleaks after TEVAR range occur in 9.5 to $15.8 \%$ of procedures, and there are limited data regarding the incidence of secondary vs primary endoleaks. Below we provide an overview of the management of endoleaks following TEVAR for aneurysms and do not address those performed for aortic dissections.

\section{- Type 1a Endoleaks}

Type 1 endoleak occurs in 3 to $16 \%$ of cases [68-71]. The treatment options are mostly endovascular with a low rate to open conversion of 3.6\% [72]. Secondary proximal type 1 endoleaks are due to an ongoing poor seal at the proximal attachment site, dilatation of the proximal attachment site or distal endograft migration. Management of secondary EL1a is primarily by extension proximally of endograft coverage by additional endografts to achieve a seal. There are a few reports of the use of EndoAnchors to treat proximal type 1 endoleaks [73, 74]. However, in general, proximal endograft coverage is the optimal treatment method. If the proximal landing zone is close to or involves the aortic arch arteries, efforts should be made to preserve flow into these arteries by surgical debranching, fenestrations, branches or chimneys. A comprehensive discussion of these advanced techniques is provided in the article entitled "Various endoluminal approaches available for treating pathologies of the aortic arch".

There are a few reports of the use of embolisation to treat EL1a where other techniques are not feasible and consideration to this option should be given if the requisite interventional skills are available for this highly challenging treatment option. Although the published data are limited to case reports, the procedural outcomes have been satisfactory. Day et al. reported two cases of successful EL1a embolisation post-TEVAR and with no recurrence at the 12 months follow-up [75]. The technique involves common femoral artery access, the use of a long sheath to access the proximal aorta, and a reverse curve-shaped catheter to engage the endoleak cavity.

Depending on the anatomy of the endoleak, detachable coils, a liquid embolic agent (e.g. Onyx) or a combination can be used to occlude the endoleak; however, the risk of embolisation to the cerebral arteries, especially when using liquid embolics should be considered. In certain cases, if the endoleak cannot be accessed from the aortic lumen, direct percutaneous access [76, 77] can be used. Patients who cannot be treated by endovascular or surgical methods are managed conservatively, with the risk of rupture that this entails.

\section{- Type 1b Endoleaks}

Similarly to EL1a, EL1b are treated by distal endograft extension. If this involves extending across the upper abdominal visceral arteries, this can be achieved in association with surgical debranching (hybrid procedure), FEVAR, BEVAR and ChEVAR. There are a few reports of embolisation of EL1b after TEVAR, and an example is shown in Fig. 6.

Patients with chronic dissection who develop late false lumen expansion and require endograft extension distally can also be treated in this way, although there are also options for endovascular occlusion of the false lumen using techniques such as the Candy-Plug procedure, Knickerbocker procedure, and embolisation of the false lumen with coils and liquid embolics. Refer to the article entitled "Role of endoluminal techniques in the management of chronic type B aortic dissection" in this special issue.

\section{- Type 2 Endoleaks}

Type 2 endoleaks after TEVAR result from retrograde flow into the aneurysm sac from branches of the thoracic aorta, but are less common compared to EVAR, with a reported incidence of $3.3 \%$ in the EUROSTAR Registry [78]. The most common cause of an EL2 post-TEVAR is retrograde flow from the left subclavian artery in patients where stent grafts have been placed across the origin of the left subclavian artery. If there is an increase in sac size, the proximal subclavian artery should be embolised with a plug or coils from the ipsilateral brachial or radial artery access, taking care to avoid the origin of the left vertebral artery, so that perfusion to the left arm via the left vertebral artery is preserved.

Type 2 endoleaks may also arise from other branches of the thoracic aorta such as the intercostal and bronchial arteries. These are usually managed conservatively, unless there is an increase in the sac size that can only be attributed to the EL2 [72]. Although challenging to treat, embolisation of these EL2 may be feasible by the transarterial or percutaneous direct sac puncture route, although reports of the efficacy of these techniques are very limited. 

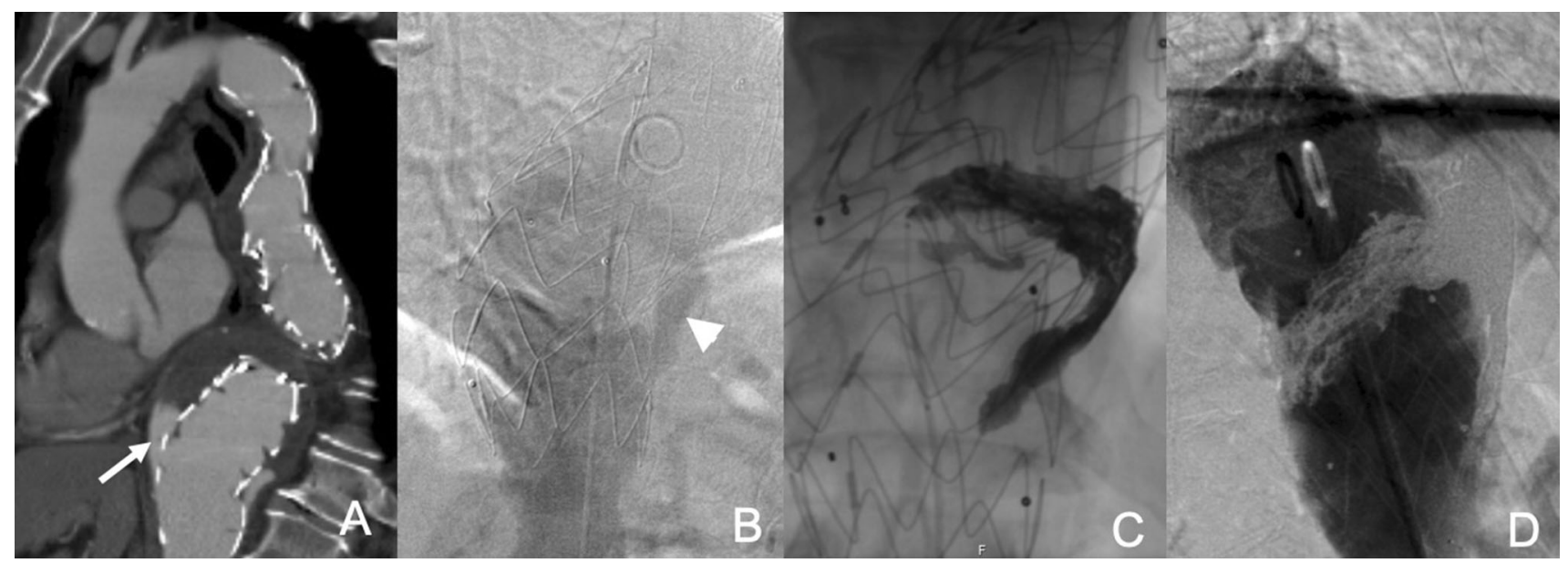

Fig. 6 EL1b embolisation following TEVAR. A Sagittal CT angiogram shows distal EL1 in patient with a thoracic endograft (arrow). B Aortic angiograms confirm EL1b (arrow head).

\section{Conclusion}

Secondary endoleaks remain an ongoing challenge following endovascular repair of the thoracic and abdominal aorta, mandating a significant burden for healthcare providers and patients in terms of surveillance and reintervention. Type 1 and 3 endoleaks result from direct communication between the high-pressure intraluminal flow in the aortoiliac vessels and the aortic sac. The significance of these is well understood, requiring prompt treatment, which includes endovascular and surgical options. Type 2 endoleak management remains a subject of debate however, with embolisation as the mainstay treatment reserved for persistent cases with a significant sac size increase.

Funding No grants or funding has been provided for this study.

\section{Compliance with Ethical Standards}

Conflict of interest The authors declare that they have no conflict of interest.

Informed consent For this type of study, informed consent is not required.

Consent for publication For this type of study, consent for publication is not required.

Open Access This article is licensed under a Creative Commons Attribution 4.0 International License, which permits use, sharing, adaptation, distribution and reproduction in any medium or format, as long as you give appropriate credit to the original author(s) and the source, provide a link to the Creative Commons licence, and indicate if changes were made. The images or other third party material in this article are included in the article's Creative Commons licence, unless indicated otherwise in a credit line to the material. If material is not included in the article's Creative Commons licence and your intended
C Embolisation of the endoleak cavity with via a microcatheter. D Final angiogram shows successful endoleak embolisation

use is not permitted by statutory regulation or exceeds the permitted use, you will need to obtain permission directly from the copyright holder. To view a copy of this licence, visit http://creativecommons. org/licenses/by/4.0/.

\section{References}

1. Wanhainen A, Verzini F, Van Herzeele I, et al. Editor's choiceeuropean society for vascular surgery (ESVS) 2019 clinical practice guidelines on the management of abdominal aorto-iliac artery aneurysms. Eur J Vasc Endovasc Surg. 2019;57:8-93.

2. Stavropoulos SW, Clark TWI, Carpenter JP, et al. Use of CT angiography to classify endoleaks after endovascular repair of abdominal aortic aneurysms. J Vasc Interv Radiol. 2005;16:663-7.

3. Rozenblit AM, Patlas M, Rosenbaum AT, et al. Detection of endoleaks after endovascular repair of abdominal aortic aneurysm: value of unenhanced and delayed helical CT acquisitions. Radiology. 2003;227:426-33.

4. Rand T, Uberoi R, Cil B, et al. Quality improvement guidelines for imaging detection and treatment of endoleaks following endovascular aneurysm repair (EVAR). Cardiovasc Intervent Radiol. 2013;36:35-45.

5. Orgera G, Tipaldi MA, Laurino F, et al. Techniques and future perspectives for the prevention and treatment of endoleaks after endovascular repair of abdominal aortic aneurysms. Insights Into Imaging. 2019. https://doi.org/10.1186/s13244-019-0774-yEpub ahead of print 2019.

6. Faries PL, Cadot H, Agarwal G, et al. Management of endoleak after endovascular aneurysm repair: cuffs, coils, and conversion. J Vasc Surg. 2003;37:1155-61.

7. Veith FJ, Baum RA, Ohki T, et al. Nature and significance of endoleaks and endotension: summary of opinions expressed at an international conference. J Vasc Surg. 2002;35:1029-35.

8. Antoniou GA, Georgiadis GS, Antoniou SA, et al. Late rupture of abdominal aortic aneurysm after previous endovascular repair: a systematic review and meta-analysis. $J$ Endovas Ther. 2015;22:734-44.

9. Naughton PA, Garcia-Toca M, Rodriguez HE, et al. Endovascular treatment of delayed type 1 and 3 endoleaks. Cardiovasc Intervent Radiol. 2011;34:751-7. 
10. Mascoli C, Faggioli G, Gallitto E, et al. Planning and endograft related variables predisposing to late distal type i endoleaks. Eur J Vasc Endovasc Surg. 2019;58:334-42.

11. Ullery BW, Tran K, Itoga NK, et al. Natural history of gutterrelated type Ia endoleaks after snorkel/chimney endovascular aneurysm repair. J Vasc Surg. 2017;65:981-90.

12. Spanos K, Rohlffs F, Panuccio G, et al. Outcomes of endovascular treatment of endoleak type Ia after EVAR: a systematic review of the literature. J Cardiovasc Surg. 2019;60:175-85.

13. Donas KP, Telve D, Torsello G, et al. Use of parallel grafts to save failed prior endovascular aortic aneurysm repair and type Ia endoleaks. J Vasc Surg. 2015;62:578-84.

14. Perini P, Bianchini Massoni C, Mariani E, et al. Systematic review and meta-analysis of the outcome of different treatments for type 1a endoleak after EVAR. Ann Vasc Surg. 2019;60(435-446):e1.

15. Jordan WD, Mehta M, Varnagy D, et al. Results of the ANCHOR prospective, multicenter registry of endoanchors for type Ia endoleaks and endograft migration in patients with challenging anatomy. J Vasc Surg. 2014;60(885-892):e2.

16. Schiattarella G, Magliulo F, Laurino F, et al. Transradial approach for the endovascular treatment of type I endoleak after aortic aneurysm repair: a case report. BMC Surg. 2013;13:S47.

17. Gandini R, Del GC, Abrignani S, et al. Inexplicable late type Ia endoleak associated with the low-profile ovation endograft in a patient with favorable neck anatomy: treatment with transcaval coil embolization. J Endovasc Ther. 2015;22:426-30.

18. Massimi TM, Kostun ZW, Woo EY. Transcaval embolization of a type I gutter endoleak after three-vessel chimney endovascular aneurysm repair. J Vasc Surg. 2017;65:1515-7.

19. Choi SY, Won JY, Lee DY, et al. Percutaneous transabdominal approach for the treatment of endoleaks after endovascular repair of infrarenal abdominal aortic aneurysm. Korean J Radiol. 2010;11:107-14.

20. Chun J-Y, Morgan R. Transcatheter embolisation of type 1 endoleaks after endovascular aortic aneurysm repair with Onyx: when no other treatment option is feasible. Eur J Vasc Endovasc. 2013;45:141-4.

21. Ameli-Renani S, Pavlidis V, Morgan RA. Early and midterm outcomes after transcatheter embolization of type I endoleaks in 25 patients. J Vasc Surg. 2017;65:346-55.

22. Ameli-Renani S, Das R, Weller A, et al. Embolisation of a proximal type i endoleak post-nellix aortic aneurysm repair complicated by reflux of onyx into the nellix endograft limb. Cardiovasc Intervent Radiol. 2015;38:747-51.

23. Marcelin C, Le Bras Y, Petitpierre F, et al. Embolization for persistent type Ia endoleaks after chimney endovascular aneurysm repair with Onyx ${ }^{\circledR}$. Diagnostic and Interventional Imaging. 2017;98:849-55.

24. Ameli-Renani S, Morgan RA. Transcatheter embolisation of proximal type 1 endoleaks following endovascular aneurysm sealing (EVAS) using the nellix device: technique and outcomes. Cardiovasc Intervent Radiol. 2015;38:1137-42.

25. Marchiori E, Herten M, Bosiers M, et al. Effectiveness of intraarterial aneurysm sac embolization for type ia endoleak after endovascular aneurysm repair. J Vasc Interv Radiol. 2019;30:531-8.

26. Sheehan MK, Barbato J, Compton CN, et al. Effectiveness of coiling in the treatment of endoleaks after endovascular repair. J Vasc Surg. 2004;40:430-4.

27. Henrikson O, Roos H, Falkenberg M. Ethylene vinyl alcohol copolymer (Onyx) to seal type 1 endoleak. Tech Vasc. 2011;19:77-81.

28. Saeed Kilani M, Izaaryene J, Cohen F, et al. Ethylene vinyl alcohol copolymer $\left(\right.$ Onyx $\left.{ }^{\circledR}\right)$ in peripheral interventional radiology: indications, advantages and limitations. Diagn Interv Imaging. 2015;96:319-26.

29. Massoni CB, Mascoli C, Perini P, et al. Endovascular treatments for type $\mathrm{Ib}$ endoleaks after aorto-iliac aneurysms exclusion: midterm results. Int Angiol. 2018;37:384-9.

30. Yu H, Isaacson AJ, Dixon RG, et al. Comparison of type II endoleak embolizations: embolization of endoleak nidus only versus embolization of endoleak nidus and branch vessels. J Vasc Interv Radiol. 2017;28:176-84.

31. El Batti S, Cochennec F, Roudot-Thoraval F, et al. Type II endoleaks after endovascular repair of abdominal aortic aneurysm are not always a benign condition. J Vasc Surg. 2013;57:1291-7.

32. Brown A, Saggu GK, Bown MJ, et al. Type II endoleaks: challenges and solutions. Vascular Health and Risk Management. 2016;12:53-63.

33. Sidloff DA, Gokani V, Stather PW, et al. Type II endoleak: conservative management is a safe strategy. Eur J Vasc Endovasc Surg. 2014;48:391-9.

34. Karthikesalingam A, Thrumurthy SG, Jackson D, et al. Current evidence is insufficient to define an optimal threshold for intervention in isolated type II endoleak after endovascular aneurysm repair. J Endovasc Ther. 2012;19:200-8.

35. Ultee KHJ, Büttner S, Huurman R, et al. Editor's Choice-systematic review and meta-analysis of the outcome of treatment for type II endoleak following endovascular aneurysm repair. Eur J Vasc Endovasc Surg. 2018;56:794-807.

36. Powell JT, Sweeting MJ, Ulug P, et al. Meta-analysis of individual-patient data from EVAR-1, DREAM, OVER and ACE trials comparing outcomes of endovascular or open repair for abdominal aortic aneurysm over 5 years. $\mathrm{Br} \mathrm{J}$ Surg. 2017;104:166-78.

37. Chung R, Morgan RA. Type 2 endoleaks post-evar: current evidence for rupture risk, intervention and outcomes of treatment. Cardiovasc Interv Radiol. 2015;38(3):507-22.

38. Chung R, Morgan R. Technical note: "remote" transarterial embolisation technique of lumbar artery type 2 endoleaks with Onyx. EJVES Extra. 2014;27:e32-e3333.

39. Spanos K, Tsilimparis N, Larena-Avellaneda A, et al. Systematic review of laparoscopic ligation of inferior mesenteric artery for the treatment of type II endoleak after endovascular aortic aneurysm repair. J Vasc Surg. 2017;66:1878-84.

40. Sarac TP, Gibbons C, Vargas L, et al. Long-term follow-up of type II endoleak embolization reveals the need for close surveillance. J Vasc Surg. 2012;55:33-40.

41. Coppi G, Saitta G, Gennai S, et al. Transealing: a novel and simple technique for embolization of type 2 endoleaks through direct sac access from the distal stent-graft landing zone. Eur J Vasc Endovasc Surg. 2014;47:394-401.

42. Ameli-Renani S, Pavlidis V, Mailli L, et al. Transiliac paraendograft embolisation of type 2 endoleak: an alternative approach for endoleak management. Cardiovasc Intervent Radiol. 2016;39:279-83.

43. Ierardi AM, Franchin M, Fontana F, et al. The role of ethylenevinyl alcohol copolymer in association with other embolic agents for the percutaneous and endovascular treatment of type Ia endoleak. Radiol Med. 2018;123:638-42.

44. Stenson KM, Patterson BO, Grima MJ, et al. Midterm results of endovascular aneurysm sealing to treat abdominal aortic aneurysm. J Vasc Surg. 2019;69(53-62):e1.

45. van den Ham LH, Holden A, Savlovskis J, et al. Editor's choice-occurrence and classification of proximal type i endoleaks after endovascular aneurysm sealing using the Nellix ${ }^{\mathrm{TM}}$ device. Eur J Vasc Endovasc Surg. 2017;54:729-36.

46. Graif A, Vance AZ, Garcia MJ, et al. Transcatheter embolization of type i endoleaks associated with endovascular abdominal 
aortic aneurysm repair using ethylene vinyl alcohol copolymer. Vasc Endovasc Surg. 2017;51:28-322.

47. Eberhardt KM, Sadeghi-Azandaryani M, Worlicek S, et al. Treatment of type I endoleaks using transcatheter embolization with onyx. J Endovasc Ther. 2014;21:162-71.

48. Katada Y, Kondo S, Kondo T, et al. Endovascular treatment for type Ia major endoleak after endovascular aneurysm repair. J Vasc Surg. 2014;59:1430-1.

49. Choi SY, Lee DY, Lee KH, et al. Treatment of type i endoleaks after endovascular aneurysm repair of infrarenal abdominal aortic aneurysm: usefulness of $N$-butyl cyanoacrylate embolization in cases of failed secondary endovascular intervention. J Vasc Interv Radiol. 2011;22:155-62.

50. Lu Q, Feng J, Yang Y, et al. Treatment of type I endoleak after endovascular repair of infrarenal abdominal aortic aneurysm: success of fibrin glue sac embolization. J Endovasc Ther. 2010;17:687-93.

51. Grisafi JL, Boiteau G, Detschelt E, et al. Endoluminal treatment of type IA endoleak with Onyx. J Vasc Surg. 2010;52:1346-9.

52. Loffroy R, Lin M, Ricolfi F, et al. Transarterial microcoil embolization of a type Ia endoleak after EVAR using a balloon remodeling technique. Vasc Med. 2010;15:513-4.

53. Golzarian J, Maes EB, Sun S. Endoleak: treatment options. Techn Vasc Interv Radiol. 2005;8:41-9.

54. Maldonado TS, Rosen RJ, Rockman CB, et al. Initial successful management of type I endoleak after endovascular aortic aneurysm repair with n-butyl cyanoacrylate adhesive. J Vasc Surg. 2003;38:664-70.

55. Amesur NB, Zajko AB, Orons PD, et al. Embolotherapy of persistent endoleaks after endovascular repair of abdominal aortic aneurysm with the ancure-endovascular technologies endograft system. J Vasc Interv Radiol: JVIR. 1999;10:1175-82.

56. Zener R, Oreopoulos G, Beecroft R, et al. Transabdominal direct sac puncture embolization of type II endoleaks after endovascular abdominal aortic aneurysm repair. J Vasc Interv Radiol. 2018;29:1167-73.

57. Carrafiello G, Ierardi AM, Radaelli A, et al. Unenhanced cone beam computed tomography and fusion imaging in direct percutaneous sac injection for treatment of Type II endoleak: technical note. Cardiovasc Intervent Radiol. 2016;39:447-52.

58. Haq IU, Kelay A, Davis M, et al. Ten-year single-centre experience with type II endoleaks: intervention versus observation. Vasc Med (United Kingdom). 2017;22:316-23.

59. Marcelin C, Le Bras Y, Petitpierre F, et al. Safety and efficacy of embolization using Onyx ${ }^{\circledR}$ of persistent type II endoleaks after abdominal endovascular aneurysm repair. Diagnostic and Interventional Imaging. 2017;98:491-7.

60. Yang RY, Tan KT, Beecroft JR, et al. Direct sac puncture versus transarterial embolization of type II endoleaks: an evaluation and comparison of outcomes. Vascular. 2017;25:227-33.

61. Stavropoulos SW, Park J, Fairman R, et al. Type 2 endoleak embolization comparison: translumbar embolization versus modified transarterial embolization. J Vasc Interv Radiol. 2009;20:1299-302.

62. Guo Q, Zhao J, Ma Y, et al. A meta-analysis of translumbar embolization versus transarterial embolization for type II endoleak after endovascular repair of abdominal aortic aneurysm. J Vasc Surg. 2019;71(3):1-7.

63. Sidloff DA, Stather PW, Choke E, et al. Type II endoleak after endovascular aneurysm repair. Br J Surg. 2013;100:1262-70.

64. Maleux G, Poorteman L, Laenen A, et al. Incidence, etiology, and management of type III endoleak after endovascular aortic repair. J Vasc Surg. 2017;66(4):1056-64.

65. Green N, Sidloff DA, Stather PW, et al. Endoleak after endovascular aneurysm repair: current status. Rev Vasc Med. 2014;2:43-7.
66. Clouse WD, Hallett JW, Schaff HV, et al. Acute aortic dissection: population-based incidence compared with degenerative aortic aneurysm rupture. Mayo Clin Proc. 2004;79:176-80.

67. Bickerstaff LK, Pairolero PC, Hollier LH, et al. Thoracic aortic aneurysms: a population-based study. Surgery. 1982;92:1103-8.

68. Makaroun MS, Dillavou ED, Wheatley GH, et al. Five-year results of endovascular treatment with the Gore TAG device compared with open repair of thoracic aortic aneurysms. J Vasc Surg. 2008;47:912-8.

69. Foley PJ, Criado FJ, Farber MA, et al. Results with the Talent thoracic stent graft in the VALOR trial. J Vasc Surg. 2012;56(1214-1221):e1.

70. Fairman RM, Tuchek JM, Lee WA, et al. Pivotal results for the medtronic valiant thoracic stent graft system in the VALOR II trial. J Vasc Surg. 2012;56(1222-1231):e1.

71. Shah AA, Barfield ME, Andersen ND, et al. Results of thoracic endovascular aortic repair 6 years after United States food and drug administration approval. Ann Thorac Surg. 2012;94:1394-9.

72. Ricotta JJ. Endoleak management and postoperative surveillance following endovascular repair of thoracic aortic aneurysms. J Vasc Surg. 2010;2010(52):91S-99.

73. Menon RS, Muetterties C, Moser GW, et al. Endoanchor stenting for the repair of a Type I endoleak in the aortic arch following the endovascular repair of a Kommerrell's diverticulum. J Card Surg. 2016;31:541-3.

74. Hogendoorn W, Schlösser FJV, Aruny JE, et al. Successful treatment of a proximal type I endoleak with helifx endoanchors. Ann Vasc Surg. 2014;28(737):e13-17.

75. Day CP, Buckenham TM, Laing AD. Embolization of proximal type 1 endoleak using n-butyl 2-cyanoacrylate after endovascular repair of the thoracic aorta: Two case reports. J Vasc Interv Radiol. 2011;22:105-7.

76. Bangard C, Franke M, Pfister R, et al. Thoracic type Ia endoleak: Direct percutaneous coil embolization of the aortic arch at the blood entry site after TEVAR and double-chimney stent-grafts. Eur Radiol. 2014;24:1430-4.

77. Katada Y, Kondo S, Tsuboi E, et al. Type IA endoleak embolization after TEVAR via direct transthoracic puncture. Japanese Journal of Radiology. 2015;33:169-72.

78. Leurs LJ, Harris PL, Buth J, et al. Secondary interventions after elective endovascular repair of degenerative thoracic aortic aneurysms: results of the european collaborators registry (EUROSTAR). J Vasc Interv Radiol. 2007;18:491-5.

79. Ribé L, Bicknell CD, Gibbs RG, et al. Long-term results of intraarterial onyx injection for type II endoleaks following endovascular aneurysm repair. Vascular. 2017;25:266-71.

80. Wojtaszek M, Wnuk E, Maciag R, et al. Improving the results of transarterial embolization of type 2 endoleaks with the embolic polymer Onyx. Wideochirurgia I Inne Tech Maloinwazyjne. 2016;11:259-67.

81. Hongo N, Kiyosue H, Shuto R, et al. Double coaxial microcatheter technique for transarterial aneurysm sac embolization of type II endoleaks after endovascular abdominal aortic repair. J Vasc Interv Radiol. 2014;25:709-16.

82. Müller-Wille R, Wohlgemuth WA, Heiss P, et al. Transarterial embolization of type II endoleaks after EVAR: the role of ethylene vinyl alcohol copolymer (Onyx). Cardiovasc Intervent Radiol. 2013;36:1288-95.

83. Funaki B, Birouti N, Zangan SM, et al. Evaluation and treatment of suspected type II endoleaks in patients with enlarging abdominal aortic aneurysms. J Vasc Interv Radiol. 2012;23:866-72.

84. Scali ST, Vlada A, Chang CK, et al. Transcaval embolization as an alternative technique for the treatment of type II endoleak after endovascular aortic aneurysm repair. J Vasc Surg. 2013;57:869-74. 
85. Gandini R, Chiocchi M, Loreni G, et al. Treatment of type II endoleak after endovascular aneurysm repair: the role of selective vs. nonselective transcaval embolization. J Endovasc Ther. 2014;21:714-22.

86. Giles KA, Fillinger MF, De Martino RR, et al. Results of transcaval embolization for sac expansion from type II endoleaks after endovascular aneurysm repair. J Vasc Surg. 2015. https:// doi.org/10.1016/j.jvs.2014.12.002.
87. Mansueto G, Cenzi D, Scuro A, et al. Treatment of type II endoleak with a transcatheter transcaval approach: results at 1-year follow-up. J Vasc Surg. 2007;45:1120-7.

Publisher's Note Springer Nature remains neutral with regard to jurisdictional claims in published maps and institutional affiliations. 